\title{
Small-scale species richness in forest canopy gaps: the role of niche limitation versus the size of the species pool
}

\author{
Duncan, Richard P. ${ }^{*}$ Buckley, Hannah L. ${ }^{1}$, Urlich, Stephen C., Stewart, Glenn H. \\ \& Geritzlehner, Julie
}

\author{
Soil, Plant and Ecological Sciences Division, P.O. Box 84, Lincoln University, Canterbury, New Zealand; \\ ${ }^{1}$ Present address: Department of Biological Sciences, University of Alberta, Edmonton, AB, T6G 2E9, Canada; \\ *Corresponding author;Tel.+643325 2811; Fax+643325 3843; E-mail duncanr@lincoln.ac.nz
}

\begin{abstract}
The form of the relationship between local species richness and the number of species in the surrounding region can be used as a test between competing theories of community structure. For 32 canopy gaps in New Zealand Nothofagus forest, we examined the relationship between the number of vascular plant species in $0.2-\mathrm{m}^{2}$ quadrats within the gap and the species richness of the whole gap. We found no evidence that competition for a limited number of niches placed an upper limit on the number of locally co-occurring species. Rather, the mean number of species in quadrats within canopy gaps increased in direct proportion to gap species richness. This relationship held after we controlled for potentially confounding factors, including variation in forest floor substrate, and gap size, age, shape and orientation. Our results suggest that even over relatively small spatial scales, local species richness can be constrained by the size of the species pool in the immediately surrounding region.
\end{abstract}

Keywords: Coexistence; Competitive exclusion; Local richness; Regional richness; Saturation; Spatial scale.

\section{Introduction}

Much ecological theory assumes that interspecific interactions, such as competition and predation, are the primary determinants of species composition and diversity in local communities (Hutchinson 1959; MacArthur 1972; Tilman 1982; Roughgarden 1989; Pimm 1991). The outcome of such interactions may be apparent as 'assembly rules' - restrictions on the number or identity of species that co-occur in a given area (Diamond 1975; Wilson et al. 1987; Wilson \& Sykes 1988). For example, the concept of 'niche limitation' supposes that the number of species that can coexist in a local area is constrained by the number of available niches, with additional species excluded by competition. Given that a local area will contain a limited number of niches and that there are sufficient species to fill those niches (i.e., the local area is saturated with species), niche limitation should result in an upper limit to local species richness.
Wilson et al. (1987) and Palmer (1987) both suggested that if such a limit exists, it should be evident as lower variance in the species richness of sample quadrats than expected under a null model, the appropriate null model being one in which there are no restrictions on the quadrats species can occupy. Using successive refinements of this quadrat variance approach, Wilson and coworkers have searched extensively for evidence of a limit to species richness in different plant communities, at a range of sample scales, and with mixed results (Wilson et al. 1987; Wilson \& Sykes 1988; Watkins \& Wilson 1992; Wilson et al. 1992; Bycroft et al. 1993; Wilson et al. 1995; see also Zobel et al. 1993; van der Maarel et al. 1995). In general, they have found significantly low variance in quadrat richness only at quadrat sizes that are small relative to the size of the plants being sampled (in grassland, typically at quadrat sizes $\leq 10$ $\mathrm{cm}^{2}$ ), suggesting that competitive exclusion limits the number of locally co-occurring species (an assembly rule), but that its effects are evident only at the spatial scale at which neighbouring plants interact.

An alternative view of local community assembly downplays the importance of biotic interactions and stresses that the availability of species from the surrounding region can determine local species composition and diversity (Ricklefs 1987; Cornell \& Lawton 1992; Zobel 1992; Eriksson 1993; van der Maarel \& Sykes 1993, 1997; we use the term region to describe an area of any size within which smaller local areas are embedded). In this view, dispersal and recruitment limitation, rather than competition for a limited number of niches, constrains the number and identity of species that co-occur in a local area (Hubbell \& Foster 1986). Local areas may differ in the number of species they contain because different numbers of species are available to colonize each local area from the surrounding region (Lawton 1982; Cornell 1985; Hugueny \& Paugy 1995; Cornell \& Karlson 1996; Pärtel et al. 1996; Caley \& Schluter 1997).

One way to distinguish between these alternative 


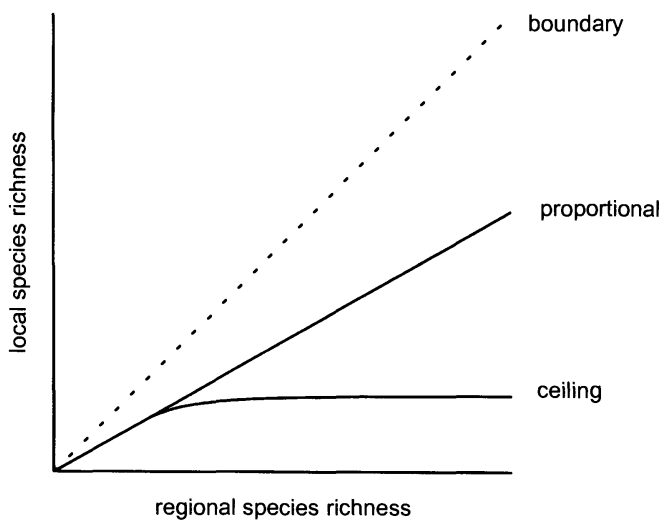

Fig. 1. Two theoretical relationships between local and regional species richness (from Cornell \& Lawton 1992; Cornell 1993). The line labelled 'ceiling' shows the form of the relationship expected if competition places an upper limit on the number of locally co-occurring species, the line labelled 'proportional' shows the relationship expected if local richness is limited by availability of species from the regional pool, and the dashed line labelled 'boundary' marks the upper limit to local richness set by exhaustion of the regional species pool.

models of community assembly (niche limitation vs. the size of the species pool) is to examine the form of the relationship between local species richness and the number of species in the surrounding region (Ricklefs 1987; Cornell \& Lawton 1992). If competition for a limited number of niches limits local species richness then, all else being equal, a plot of local versus regional richness should have a ceiling marking an upper limit to the number of locally co-occurring species (Fig. 1). In contrast, if local richness is limited by the availability of species, then local richness should increase in proportion to the number of species in the surrounding regional pool.

In this paper, we search for an upper limit to smallscale plant species richness by examining how the number of vascular plant species in $0.2-\mathrm{m}^{2}$ quadrats within forest canopy gaps varies in relation to the total number of species in the surrounding gap. If competition for a limited number of niches constrains the number of species in $0.2-\mathrm{m}^{2}$ quadrats, then quadrat species richness should have an upper limit that is independent of gap species richness. Alternatively, if local species richness is limited by the size of the species pool in the immediately surrounding region, then quadrat and gap species richness should be positively correlated.

\section{Methods}

Study site

The study site is an old-growth Nothofagus stand at
Rough Creek in the Maruia Valley, northwest South Island, New Zealand. 50 canopy gaps ranging in size from $100-950 \mathrm{~m}^{2}$ (the expanded gap area, see Data collection) had previously been mapped in the stand, and a description of the study area, along with information on how the canopy gaps were identified and mapped, is in Stewart et al. (1991). Briefly, the stand is on a recent valley floor terrace on soils formed from alluvial sand and silt. Rainfall in the study area is in the range $2500-2700 \mathrm{~mm} / \mathrm{yr}$ and mean air temperature ranges from 5 to $15^{\circ} \mathrm{C}$. The forest canopy is dominated almost exclusively by trees of Nothofagus fusca (Hook.f.) Oerst. and $N$. menziesii (Hook.f.) Oerst.

\section{Data collection}

In December 1995 and January 1996, we sampled 32 of the canopy gaps identified in Stewart et al. (1991), with the sampled gaps chosen a priori to cover the range of gap sizes and ages in the stand. For each gap, the length (the longest axis from the boles of trees on the gap edges), and the width (the longest axis at right angles to the length) were used to define the boundaries of the expanded gap (sensu Runkle 1982).

Differences in the species composition of forest canopy gaps are often related to differences in gap area and age, at least in part because the size and age of canopy openings influence conditions such as the light, humidity, and temperature environments within gaps (Chazdon \& Fletcher 1984; Collins et al. 1985; Dirzo et al. 1992). Because they correlate broadly with gap environments, we used expanded gap area and age, along with gap orientation (degrees of the longest axis from north) and a measure of gap shape (gap length / gap width), as proxy variables to characterize environmental differences between gaps. Estimates of gap age were taken from Stewart et al. (1991); the gaps ranged in age from 9 to 72 years $($ mean $=27$ ).

If quadrat species richness is a function of gap richness, it makes sense to ask what determines gap richness. Because substrate heterogeneity is hypothesized to influence gap species richness (Orians 1982), we measured differences in the availability of forest floor substrates among gaps. Four to eight transect lines were located through each gap. Two of the transects ran along the length and width axes that defined the expanded gap, and the remaining transects were located parallel to the first two, but positioned at 5-m intervals on either side. Larger, wider gaps had more transects. We measured the proportions of five forest floor substrates (forest floor, log, stump, mound, and pit) by recording the distance along the transect lines that overlaid each substrate. A log was defined as a fallen branch or bole wider than $0.33 \mathrm{~m}$, stumps were the bases of dead stand- 
ing or snapped trees, mounds were the uplifted root plate and soil associated with fallen, uprooted trees, and pits were the adjacent depression in the forest floor.

We sampled the vegetation at 5-m intervals along each transect line. At each sample point, we placed a $0.2-\mathrm{m}^{2}(0.6 \mathrm{~m} \times 0.33 \mathrm{~m})$ quadrat on the nearest of each of the five substrates within a 5-m radius. If a substrate was absent within $5-\mathrm{m}$, no quadrat was measured for that substrate at that point. In each quadrat, we recorded all vascular plant species rooted in the quadrat, and characterized the local environment by recording the substrate class and noting whether the quadrat was in the canopy gap (open canopy quadrat), or was located directly under the overhanging canopy of trees on the edge of the expanded gap (gap edge quadrat). We measured 1253 quadrats in the 32 canopy gaps, with the number of quadrats in any one gap ranging from 12 to 122 . We measured total gap species richness by carefully searching each expanded gap for additional plant species that were not recorded in the quadrat sampling.

\section{Data analysis}

We quantified substrate heterogeneity within canopy gaps by calculating Simpson's heterogeneity index ( $D=\Sigma p_{i}{ }^{2}$, where $p_{i}$ is the proportion of the $i$ th substrate class in a gap) and subtracting it from one (Magurran 1988). This index takes the number of substrates and substrate evenness into account and, for a given number of substrates, has highest value when all substrate classes are found in equal proportions.

We used Least Squares Regression to examine the relationship between mean quadrat species richness within canopy gaps and gap species richness. If niche limitation sets a limit to local species richness, then mean quadrat richness should be independent of gap richness and the slope of the regression line should be zero. Therefore, a significant positive relationship between mean quadrat and gap species richness would reject the hypothesis of niche limitation. Alternatively, there may be an upper limit to local species richness, but that limit is reached only in the most species-rich gaps where there were sufficient colonists to saturate all the local niches. We would then expect a curvilinear relationship between mean quadrat and gap species richness. We tested for a relationship of this form by testing if the inclusion of a second order polynomial in the regression model resulted in a significant improvement in model fit (Cresswell et al. 1995; Cornell \& Karlson 1996; Caley $\&$ Schluter 1997). In all cases, we examined the form of the relationship between mean quadrat and gap species richness first, by including both variables alone in a simple regression model and second, after including other factors (such as gap area, age, shape and orientation) in a multiple regression model to statistically remove their potentially confounding effects.

Cresswell et al. (1995) point out that values for local and regional species richness will not be independent if there are species restricted to only one local area within a region. If uncorrected, this non-independence could bias the outcome of statistical tests and, depending on circumstances, make a significant positive slope more or less likely to be observed. Because distinguishing among the alternative hypotheses relies on a test of the slope of the relationship between local and regional species richness, it is important to correct for this source of bias. Unfortunately, we could not apply the method that Cresswell et al. (1995) advocate (calculating regional species richness with the local area of interest excluded from the regional data set) because our measure of local species richness is the average of many local quadrats. However, the slope of the relationship between local and regional species richness will be unbiased if the number of species restricted to only one local area within a region is uncorrelated with regional species richness (see Fig. 1a in Cresswell et al. 1995). We tested if this was true for our data by summing the number of species found in only one quadrat within each canopy gap and correlating this with the total number of species in each gap (excluding those species found in only one quadrat). There was no significant correlation between the number of single-quadrat species and the number of species in the surrounding gap (linear regression, $\left.r^{2}=0.07, n=32, P=0.14\right)$.

\section{Results}

Total-gap species richness was higher in canopy gaps of greater area and with higher substrate diversity, but was not significantly correlated with any of the other characteristics that we used as proxies to describe gap environments (Table 1). Gap area and substrate heterogeneity were themselves positively correlated $(r=0.45$, $n=32, P<0.01$ ).

In simple regression, none of the characteristics that we used as proxy variables to characterize gap environments (age, area, orientation, shape, or substrate diversity) were significant predictors of mean quadrat species richness within canopy gaps, although area and shape explained a significant but small amount of variation in multiple regression (Table 2). In contrast, gap species richness was a highly significant predictor of mean quadrat species richness, both in simple regression and after variation in other gap characteristics had been accounted for in multiple regression (Fig. 2, Table 2). In both cases the regression slope was positive. While the addition of a quadratic term for gap richness resulted in 
Table 1. Correlation coefficients $(r)$ of gap species richness with gap characteristics $(n=32)$.

\begin{tabular}{ll}
\hline Gap characteristic & $r$ \\
\hline Substrate heterogeneity $(1-D)$ & $0.39 *$ \\
Gap area & $0.65 * * *$ \\
Gap age & 0.14 \\
Gap shape & 0.27 \\
Gap orientation & 0.07 \\
& \\
$* P<0.05, * * * P<0.001$ & \\
\hline
\end{tabular}

a significant, though slight improvement in model fit in simple regression (suggesting a curvilinear relationship), the quadratic term failed to enter the model once other gap characteristics had been included $(t=-0.39$, $P=0.7$ ).

Quadrat species richness did not differ between open or gap edge quadrats (One-way Analysis of Variance, $\left.F_{1,1251}=0.78, P=0.38\right)$. However, quadrat species richness differed between substrate classes with quadrats located on stump, log, and pit substrates containing fewer species than those on the forest floor and mounds (Table 3). The significant positive relationship between mean quadrat and gap species richness could be an artefact of this variation in species richness across substrate classes coupled with differences in the proportions of substrates found in gaps. To control for this possibility, we carried out regressions of mean quadrat species richness on gap species richness separately for quadrats on each substrate class. All five substrate classes

Table 2. Linear regressions, weighted by the number of quadrats per gap, with mean quadrat species richness within canopy gaps as the dependent variable and gap characteristics and gap species richness as predictor variables. The results from two regression models for each predictor variable are shown: 'Alone' is the $t$-value testing the hypothesis that the slope of the relationship between mean quadrat richness and the predictor variable does not equal 0 when the predictor is included alone in a simple regression model, and 'In complete model' is the $t$-value testing the same hypothesis after all other predictor variables have previously been included in a multiple regression model $(n=32)$.

\begin{tabular}{llc}
\hline Predictor variables & Alone & In complete model \\
\hline Substrate heterogeneity $(1-D)$ & 0.43 & 0.16 \\
Gap area & 0.52 & $2.12 *$ \\
Gap age & 0.96 & 0.85 \\
Gap shape & 0.23 & $2.30^{*}$ \\
Gap orientation & 0.06 & 0.05 \\
Gap species richness & $4.23 * * *$ & $6.26^{* * *}$ \\
& & \\
$* P<0.05, * * * P<0.001$ & & \\
\hline
\end{tabular}

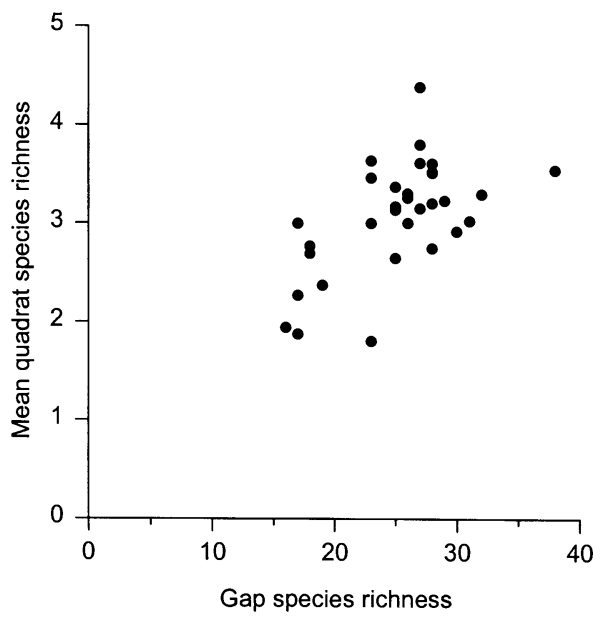

Fig. 2. Scatterplot of mean quadrat species richness within canopy gaps versus total gap species richness. Linear regression, weighted for the number of quadrats per gap, is significantly positive $\left(n=32, t=4.23, P<0.001, r^{2}=0.37\right)$.

showed a significant positive relationship between mean quadrat and gap species richness, both in simple regression and after other gap characteristics had been included in multiple regression (Table 4). The addition of a quadratic term for gap richness resulted in a significant improvement in model fit only for log substrates and only when gap richness was included alone in a simple regression model $(t=2.13, n=32, P=0.048)$. Hence, after controlling for variation in substrate class and gap characteristics, mean quadrat species richness within canopy gaps increased in direct proportion to gap species richness.

\section{Discussion}

We found no evidence of an upper limit to quadrat species richness and therefore no indication that competition for a limited number of niches constrained the number of species in $0.2-\mathrm{m}^{2}$ quadrats within forest canopy gaps. This assumes that the quadrat size we

Table 3. Mean species richness per quadrat on each of five substrate classes.

\begin{tabular}{lcc}
\hline Substrate class & $n$ & $\begin{array}{c}\text { Mean species richness / } \\
\text { quadrat } \pm \text { 1 S.D) }\end{array}$ \\
\hline Mound & 173 & $3.7 \pm 1.7$ \\
Forest floor & 467 & $3.4 \pm 1.4$ \\
Pit & 128 & $2.8 \pm 1.6$ \\
Log & 342 & $2.7 \pm 1.4$ \\
Stump & 143 & $2.6 \pm 1.4$ \\
\hline
\end{tabular}


Table 4. Linear regressions, weighted by the number of quadrats per gap, with mean quadrat species richness within canopy gaps on each of the five substrate classes as the dependent variables and gap species richness as the predictor variable. The columns 'Alone' and 'In complete model' as in Table 2. $n=$ number of gaps.

\begin{tabular}{lccc}
\hline Substrate class & $n$ & Alone & In complete model \\
\hline Mound & 27 & $3.35 * *$ & $3.04 * *$ \\
Forest floor & 32 & $2.97 * *$ & $3.63 * *$ \\
Pit & 27 & $2.45 *$ & $2.55 *$ \\
Log & 32 & $2.19 *$ & $3.15 * *$ \\
Stump & 26 & $2.40 *$ & $2.12 * *$ \\
& & & \\
$* P<0.05 ; * * P<0.01$. & & \\
\hline
\end{tabular}

selected would detect an upper limit to local species richness if one existed. Quadrat variance studies show that an upper limit to local richness is more likely to be found at fine rather than coarse sample scales (Wilson et al. 1995) and our choice of a $0.2-\mathrm{m}^{2}$ quadrat was a compromise between making our sample area as small as possible while ensuring that our quadrats were large enough to sample sufficient species to compare variation in quadrat richness. Previous studies have argued that quadrats of $1 \mathrm{~m}^{2}$ are small enough to detect niche limitation in forest communities (Bycroft et al. 1993; Zobel et al. 1993).

Nevertheless, we would most likely observe niche limitation in communities that had reached a competitive equilibrium where quadrats were saturated with species and competitively inferior species had been excluded. A potential criticism of our study is that we chose a disturbed system (transient forest canopy gaps) that may not have reached competitive equilibrium, making it unlikely that we would observe niche limitation. There are three reasons why local areas could be displaced from equilibrium. First, quadrats in recently formed gaps could still be accumulating species if insufficient time had passed for colonists to saturate all the local niches. Alternatively, quadrats in recently formed gaps could be oversaturated if there had been insufficient time for competitive sorting to have eliminated inferior competitors. There is no evidence to support either of these scenarios as both predict a significant correlation between mean quadrat richness and gap age, which we did not find (Table 2). Hence, our failure to observe niche limitation was not a consequence of sampling areas that were converging on, but had not yet reached, competitive equilibrium.

The third possibility is that competitive interactions were not strong enough to cause competitive exclusion and so limit local richness. Our results support this scenario and suggest that the availability of species in the immediately surrounding region was the key factor structuring local assemblages in the canopy gaps we studied. Our conclusion rests on two assumptions. First, we are assuming that the total number of species in a canopy gap describes the pool of species available to occupy a quadrat within that gap, an assumption we think is reasonable. In the old-growth Nothofagus forest we studied, canopy gaps are formed by the death of one or a few canopy trees and occur as discrete openings in an otherwize closed forest (Stewart et al. 1991). Most of the vascular plant species in these forests, especially understorey shrub and herbaceous species, grow in the high light environment of canopy gaps and are absent from the surrounding closed forest. Hence, canopy gaps form discrete habitat patches of high species richness separated by areas of closed forest unsuitable for most gap species. The total number of species in a canopy gap therefore describes the number of species with similar habitat requirements that, because of their proximity, are the most likely to colonize local areas within a gap.

Second, our conclusion implies a causal relationship between species richness at different spatial scales and assumes the direction of causality is that regional richness limits local richness (see also Hugueny \& Paugy 1995; Pärtel et al. 1996; Caley \& Schluter 1997). Confounding factors could generate a spurious relationship between local and regional species richness. For example, if both local and regional richness covaried in response to a third variable then we could get a positive relationship between species richness at the two spatial scales even if local richness was independent of the regional species pool. In this study, a highly significant correlation between local and regional richness persisted, and was usually strengthened, after we statistically controlled for likely confounding variables, giving us some confidence that the relationship was not artefactual.

The direction of causality follows from the above argument. Having controlled for environmental factors that can influence local species richness, there appears no reason why equivalent quadrats in species-poor gaps could not support at least the same number of species as quadrats in species-rich gaps, other than that different numbers of species were available to colonize those local areas. It follows that local quadrats were unsaturated and that gap richness must be limiting quadrat richness rather than vice versa (Cornell \& Lawton 1992; Cornell 1993).

Acknowledgements. We thank O. Eriksson, C. Newell, M. Pärtel, E. van der Maarel and J.B. Wilson for helpful comments on the manuscript. This research was supported by a Lincoln University Grant to R. Duncan and G. Stewart. 


\section{References}

Bycroft, C.M., Nicolaou, N., Smith, B. \& Wilson, J.B. 1993. Community structure (niche limitation and guild proportionality) in relation to the effect of spatial scale, in a Nothofagus forest sampled with a circular transect. N.Z.J. Ecol. 17: 95-101.

$\rightarrow$ Caley, M.J. \& Schluter, D. 1997. The relationship between local and regional diversity. Ecology 78: 70-80.

$\rightarrow$ Chazdon, R.L. \& Fletcher, N. 1984. Photosynthetic light environments in a lowland tropical rainforest in Costa Rica. $J$. Ecol. 72: 553-564.

Collins, B.S., Dunne, K.P. \& Pickett, S.T.A. 1985. Responses of forest herbs to canopy gaps. In: Pickett, S.T.A. \& White, P.S. (eds.) The ecology of natural disturbance and patch dynamics, pp. 217-234. Academic Press, San Diego, CA.

$\rightarrow$ Cornell, H.V. 1985. Species assemblages of cynipid gall wasps are not saturated. Am. Nat. 126: 565-569.

Cornell, H.V. 1993. Unsaturated patterns in species assemblages: the role of regional processes in setting local species richness. In: Ricklefs, R.E. \& Schluter, D. (eds.) Species diversity in ecological communities: historical and geographical perspectives, pp. 243-252. University of Chicago Press, Chicago, IL.

$\rightarrow$ Cornell, H.V.\& Karlson, R.H. 1996. Species richness of reefbuilding corals determined by local and regional processes. J. Anim. Ecol. 65: 233-241.

$\rightarrow$ Cornell, H.V. \& Lawton, J.H. 1992. Species interactions, local and regional processes, and limits to the richness of ecological communities: a theoretical perspective. J. Anim. Ecol. 61: 1-12.

$\rightarrow$ Cresswell, J.E., Vidal-Martinez, V.M. \& Crichton, N.J. 1995. The investigation of saturation in the species richness of communities: some comments on methodology. Oikos 72 : 301-304.

Diamond, J.M. 1975. Assembly of species communities. In: Cody, M.L. \& Diamond, J.M. (eds.) Ecology and evolution of communities, pp. 342-444. Harvard University Press, Cambridge.

$\rightarrow$ Dirzo, R., Horvitz, C., Quevedo, H. \& Lopez, A. 1992. The effects of gap size and age on the understory herb community of a tropical Mexican rain forest. J. Ecol. 80: 809-822.

Eriksson, O. 1993. The species-pool hypothesis and plant community diversity. Oikos 68: 371-374.

Hubbell, S.P. \& Foster, R.B. 1986. Biology, chance, and history in the structure of tropical rain forest tree communities. In: Diamond, J. \& Case, T.J. (eds.) Community Ecology, pp. 314-329. Harper \& Row, New York, NY.

$\rightarrow$ Hugueny, B. \& Paugy, D. 1995. Unsaturated fish communities in African rivers. Am. Nat. 146: 162-169.

$\rightarrow$ Hutchinson, G.E. 1959. Homage to Santa Rosalia, or why are there so many kinds of animals? Am. Nat. 93: 145-159.

$\rightarrow$ Lawton, J.H. 1982. Vacant niches and unsaturated communities: a comparison of bracken herbivores at sites on two continents. J. Anim. Ecol. 51: 573-595.

MacArthur, R.H. 1972. Geographical ecology. Princeton University Press, Princeton, NJ.

Magurran, A.E. 1988. Ecological diversity and its measure- ment. Princeton University Press, Princeton, NJ.

Orians, G.H. 1982. The influence of tree-falls in tropical forests in tree species richness. Trop. Ecol. 23: 255-279.

Palmer, M.W. 1987. Variability in species richness within Minnesota oldfields: a use of the variance test. Vegetatio 70: 61-64

Pärtel, M., Zobel, M., Zobel, K. \& van der Maarel, E. 1996. The species pool and its relation to species richness: evidence from Estonian plant communities. Oikos 75 : 111-117.

Pimm, S.L. 1991. The balance of nature? Chicago University Press, Chicago, IL.

$\rightarrow$ Ricklefs, R.E. 1987. Community diversity: relative roles of local and regional processes. Science 235: 167-171.

Roughgarden, J. 1989. The structure and assembly of communities. In: Roughgarden, J., May, R.M. \& Levin, S.A. (eds.) Perspectives in ecological theory, pp. 203-226. Princeton University Press, Princeton, NJ.

$\rightarrow$ Runkle, J.R. 1982. Patterns of disturbance in some old-growth mesic forests of the eastern United States. Ecology 63: 1533-1546.

$\rightarrow$ Stewart, G.H., Rose, A.B. \& Veblen, T.T. 1991. Forest development in canopy gaps in old-growth beech (Nothofagus) forests, New Zealand. J. Veg. Sci. 2: 679-690.

Tilman, D. 1982. Resource competition and community structure. Princeton University Press, Princeton, NJ.

van der Maarel, E., Noest, V. \& Palmer, M.W. Variation in species richness on small grassland quadrats: niche structure or small-scale plant mobility? J. Veg. Sci. 6: 741-752.

$\rightarrow$ van der Maarel, E. \& Sykes, M.T. 1993. Small-scale plant species turnover in a limestone grassland: the carousel model and some comments on the niche concept. J. Veg. Sci. 4: 179-188.

van der Maarel, E. \& Sykes, M.T. 1997. Rates of small-scale species mobility in alvar limestone grassland. J. Veg. Sci. 8: $199-208$

$\rightarrow$ Watkins, A.J. \& Wilson, J.B. 1992. Fine-scale community structure of lawns. J. Ecol. 80: 15-24.

$\rightarrow$ Wilson, J.B., Gitay, H. \& Agnew, A.D.Q. 1987. Does niche limitation exist? Funct. Ecol. 1: 391-397.

$\rightarrow$ Wilson, J.B., Roxburgh, S.H. \& Watkins, A.J. 1992. Limitation to plant species coexistence at a point: a study in a New Zealand lawn. J. Veg. Sci. 3: 711-714.

Wilson, J.B. \& Sykes, M.T. 1988. Some tests for niche limitation by examination of species diversity in the Dunedin area, New Zealand. N.Z. J. Bot. 26: 237-244.

$\rightarrow$ Wilson, J.B., Sykes, M.T. \& Peet, R.K. 1995. Time and space in the community structure of a species-rich limestone grassland. J. Veg. Sci. 6: 729-740.

Zobel, K., Zobel, M. \& Peet, R.K. 1993. Change in pattern diversity during secondary succession in Estonian forests. J. Veg. Sci. 4: 489-498.

$\rightarrow$ Zobel, M. 1992. Plant species coexistence - the role of historical, evolutionary and ecological factors. Oikos 65: 314-320.

Received 24 November 1997; Revision received 21 April 1998; Accepted 27 April 1998. 